\title{
CRESCIMENTO E MATURAÇÃO DOS FRUTOS E SEMENTES DE URUCUM
}

\author{
ANGELAMARIADASILVAMENDES ${ }^{2}$, ANTENOR FRANCISCO DE FIGUEIREDO $^{3}$, JOSÉ FERREIRADASILVA ${ }^{3}$
}

\begin{abstract}
RESUMO - Este experimento foi conduzido em um sistema multiextratado em Manaus - Amazonas com a finalidade de estudar o crescimento e a maturação de frutos e de sementes de urucum (Bixa orellana L.). No período de máxima floração foram marcadas cerca de 1.500 flores e, a partir desta data, uma vez por semana, colhiam-se ao acaso 45 frutos, até a idade em que os frutos atingiram a maturidade de colheita, totalizando 12 coletas. Em cada colheita, foi realizada uma descrição detalhada do estádio de desenvolvimento dos frutos. Também foi determinada a matéria seca dos frutos e das sementes; comprimento e diâmetro dos frutos; comprimento, diâmetro, umidade, viabilidade e vigor das sementes. As sementes de urucum começam a germinar aos 62 dias após a antese, quando alcançam $62,5 \%$ da matéria seca total. O crescimento das sementes com relação ao acúmulo de matéria seca apresentou um padrão sigmoidal e atingiu o valor máximo de matéria seca aos 76 dias após a antese. Nesta fase, as sementes estão com a máxima germinação e vigor, com a área da calaza circundada por anel lilás e funículo marrom e os frutos mudam de coloração de vermelha para tons amarelados caracterizando o ponto de maturidade fisiológica.
\end{abstract}

Termos para indexação: Bixa orellana, sistemas agroflorestais, qualidade fisiológica.

\section{GROWTHAND MATURATION OF URUCUM FRUITS SEEDS}

\begin{abstract}
This experiment was carried out in a multistratum system in Manaus - Amazonas with the purpose to study the growth and maturation of annato fruits and seeds (Bixa orellana L.) cultivated in this system. At the maxim blooming stage about 1.500 flowers were marked. From this stage on, 45 fruits were picked at random once a week. This was done until the fruits reached the maturation stage, totalizing 12 collections. A detailed description was made of the fruit development stage in every collection. The fruit and seed dry matter, fruit length and diameter and seed length, diameter, moisture, viability and vigor were also determined. The annato seed begins to germinate on the $62^{\text {nd }}$ day after anthesis, when it attains $62.5 \%$ maximum dry matter. About the growth of the seeds related to the dry matter a sigmoid behavior was observed, with its three distinct phases, reaching a maximum dry matter value on the $76^{\text {th }}$ day after anthesis. In this phase, the seeds reached the maximum germination and vigor stage, and the fruits were turning from reddish to yellowish hues and seeds had lilac colored chalazae part and brown funiculum, which characterizes physiological maturation.
\end{abstract}

Index terms: Bixa orellana, agroforestry system, physiological quality.

\section{INTRODUÇ̃̃O}

O cultivo em Sistemas Agroflorestais, multiextratado é formado por várias espécies, com isso, diminui-se o número de espécime por hectare e conseqüentemente, também diminui a quantidade do produto. Neste sistema, os produtos e

\footnotetext{
${ }^{1}$ Submetido em 08/03/2004. Aceito para publicação em 02/06/2005. Parte da Dissertação realizada pelo primeiro autor na Universidade Federal do Amazonas/Faculdade de Ciências Agrárias (UFAM/FCA);

${ }^{2}$ Professora voluntária da UFAM/FCA; Av. Gen. Rodrigo Otávio J. Ramos,
}

subprodutos formados são geralmente frutos, grãos, madeira e essências medicinais, não sendo encontradas na literatura, espécies domesticadas para a produção de sementes.

O urucum (Bixa orellana L.) da família Bixaceae, originária da América e cultivada na África e na Ásia (Mendonça et al., 2001) é uma espécie perene de importância nacional e

3000, CEP 9077-000, Manaus/AM, Fone-fax (092) 47 4042, amendes@ufam.edu.br;

3 Professores Doutores da UFAM/FCA, antenor@ufam.edu.br; propesp@ufam.edu.br. 
regional, onde faz parte do componente semi-arbóreo de sistemas agroflorestais. As sementes de urucum são valiosas pela característica de produzir pigmentos, que são utilizados como corante natural, nas indústrias alimentícias, farmacêutica e cosmética. Portanto, esta espécie quando cultivada em sistemas multiextratado, pode ser utilizada como produtora de sementes e a maturação fisiológica desta deve ser avaliada.

$\mathrm{O}$ ciclo de vida em plantas superiores compreende o desenvolvimento de uma semente seguido por sua germinação e o desenvolvimento pós-germinativo por meio do crescimento da planta. Ambos os períodos são marcados por eventos fisiológicos específicos relacionados às mudanças distintas no peso fresco, peso seco e conteúdo de água (Castro et al., 2004).

Crescimento e desenvolvimento são dois processos distintos, porém bastante relacionados, geralmente, os dois processos ocorrem simultaneamente. Segundo Castro et al. (2004), na maioria das sementes, o desenvolvimento pode ser dividido em três fases confluentes; a primeira fase é devido à divisão celular e a um aumento rápido no peso fresco e no conteúdo de água; depois disso, há uma fase intermediária de maturação devida, principalmente, à expansão das células e à deposição de reservas; e finalmente, o desenvolvimento da maioria das sementes termina com uma fase pré-programada da secagem ou dessecação.

De acordo com Alvarez (1999), a análise de crescimento pode ser usada para investigar a adaptação ecológica das culturas a novos ambientes, a competição entre as espécies, os efeitos de manejo e tratos culturais. Segundo Benincasa (1988), é possível detectar efeitos de deficiência do meio, possibilitando a correção dos mesmos a tempo de não comprometer a produção final.

O presente trabalho teve como objetivo estudar o processo de maturação fisiológica das sementes de urucum, tipo vermelho piloso, dentro de um sistema agroflorestal, e outras transformações de frutos e sementes que ocorrem associadas ao estádio de desenvolvimento, e que refletem a qualidade destas sementes.

\section{MATERIALE MÉTODOS}

O estudo foi realizado sob condições ecológicas de um Sistema Agroflorestal em Manaus, Amazonas. O urucuzeiro (Bixa orellana L.), tipo vermelho piloso, foi implantado em consórcio com pupunha (Bactris gasipaes H. B. K.), castanhado-brasil (Bertholletia excelsa H. B. K.) e cupuaçu (Theobroma grandiflorum Schum). Como planta de cobertura foi utilizada a puerária (Pueraria phaseoloides Benth).

No período de máxima floração, foram marcadas cerca de 1.500 flores. A partir desta data, uma vez por semana colhiam-se ao acaso 45 frutos, até a idade em que os frutos atingiram a maturidade de colheita (pouco antes da deiscência), totalizando 12 coletas.

No Laboratório de Sementes, foram avaliadas as seguintes características para cada coleta: aparência dos frutos e sementes - a partir de 20 frutos, observou-se os aspectos externos como forma, consistência e a coloração conforme Munsel (1975); tamanho dos frutos e das sementes - os frutos foram divididos em quatro repetições de cinco, efetuando-se as medidas de comprimento e diâmetro em milímetros, medidos com paquímetro digital. Também foi avaliado o número de sementes por fruto. Desses frutos foram avaliadas 40 sementes, obtidas aleatórias dos 20 frutos, divididas em quatro repetições de dez, se efetuou as medidas de comprimento e diâmetro em milímetros; matéria seca dos frutos e sementes - a matéria seca, em gramas, foi obtida dos mesmos frutos e sementes mencionados anteriormente, ou seja, vinte frutos abertos, divididos em quatro repetições de cinco e 40 sementes obtidas aleatórias dos 20 frutos divididas em quatro repetições de 10, em estufa com ventilação forçada a $75^{\circ} \mathrm{C}$, até peso constante; teor de água das sementes - foi obtido de modo similar à obtenção da matéria seca das sementes, porém obteve-se também o peso da matéria fresca para fins de cálculo segundo Brasil (1992); germinação e vigor das sementes - a porcentagem de germinação das sementes foi determinada pelo teste de germinação, considerando semente germinada a formação de plântula normal segundo Brasil (1992) e o vigor pela porcentagem de emergência no ambiente e pelo índice de velocidade de emergência (IVE). Foram beneficiados 25 frutos para a obtenção da amostra de sementes. A germinação foi avaliada com quatro repetições de 50 sementes, em bandejas de vidro transparente, sobre quatro camadas de papel de germinação tipo germitest e colocadas para germinar em câmara de germinação, sob temperatura constante de $30^{\circ} \mathrm{C}$. $\mathrm{O}$ critério de avaliação foi à formação de plântula normal, segundo Pereira (1995) para esta espécie. O vigor das sementes foi avaliado utilizando-se quatro repetições de 50 sementes, em caixas plásticas, contendo como substrato terriço de mata peneirado e colocadas para germinar em viveiro, com $30 \%$ de sombreamento.

$\mathrm{O}$ experimento foi conduzido em delineamento inteiramente casualizado, com quatro repetições, cujos tratamentos foram constituídos de épocas de colheitas. Para 
as medidas de crescimento foram ajustadas equações de regressão, procurando-se o modelo que melhor se ajustasse aos dados primários. Os resultados de germinação, emergência de plântulas, índice de velocidade de emergência e teor de água das sementes foram submetidos à análise de variância. Dados do índice de velocidade de emergência foram previamente transformados para $\sqrt{\mathrm{x}+1}$ e de germinação e teor de água foram transformados para arc.sen. $\sqrt{\%}$, conforme Ferreira (1991).

A taxa de produção das diversas características foi obtida derivando-se a equação ajustada para a característica em estudo, em relação ao tempo. Os valores da taxa de crescimento relativo foram calculados dividindo-se o valor instantâneo da derivada primeira da característica em estudo, pelos valores instantâneos estimados pela equação ajustada aos dados. O ponto de inflexão (PI) da taxa de produção foi estimado, encontrando-se a derivada segunda da equação ajustada.

\section{RESULTADOS E DISCUSSÃO}

\section{Aparência dos frutos e sementes}

Os frutos de urucum vermelho piloso aos 10 dias após antese (DAA) apresentavam coloração vermelha intenso, de consistência tenra, pêlos densos e macios e de formato cônico. Semente pequena e frágil, alongada de coloração rosa sem brilho, área da calaza e funículo de coloração esbranquiçada.

Aos 76 DAA, os frutos eram obovóides cordiformes com pêlos firmes de coloração vermelha opaco e superfície externa de tons amarelados. Semente com tegumento externo espesso (comumente chamado de arilo), de coloração vermelha escura opaca; área da calaza circundada por um anel de coloração lilás e o funículo marrom claro.

Na última colheita aos 90 DAA, os frutos apresentavamse completamente marrons com pêlos duros como espinhos, sendo que aproximadamente um quarto desses estavam abertos. A superfície das sementes estava coberta por micélios de fungos e a área da calaza e funículo de cor preto.

Os índices visuais (aparência) baseiam-se no conceito de que o processo de amadurecimento das sementes é acompanhado pelas mudanças externas do fruto. Para o urucum cultivado em sistemas agroflorestais, o índice de maturação baseado na coloração e consistência dos frutos e sementes, parece ser um bom indicativo na previsão da época de maturação e colheita pelas suas flutuações de coloração ao longo da maturação. Os frutos e sementes aos 76 dias após a antese (DAA), apresentaram as características visuais nitidamente diferentes das outras coletas.

Segundo Pimentel (1985), de um modo geral, os frutos de urucum não atingem a maturação simultaneamente assim sendo, a colheita é efetuada quando se verifica que dois a três frutos por cacho adquirem uma coloração acastanhada

\section{Matéria seca dos frutos e sementes}

$\mathrm{O}$ fruto de urucum apresentou crescimento, baseada na matéria seca, com três fases distintas (Figura 1A). No início o crescimento foi lento, permanecendo até os 31 DAA. Segundo Nacif (1991) esta fase corresponde à divisão celular que seria estimulada por fito-hormônios, associada à polinização.

A partir dos 31 DAA até aos 57 DAA o acúmulo de matéria seca foi acelerado, e após esta fase o crescimento foi novamente lento, até o fruto atingir o máximo acúmulo de matéria seca com valor $11,6 \mathrm{~g}$, que ocorreu aos 76 DAA. Após
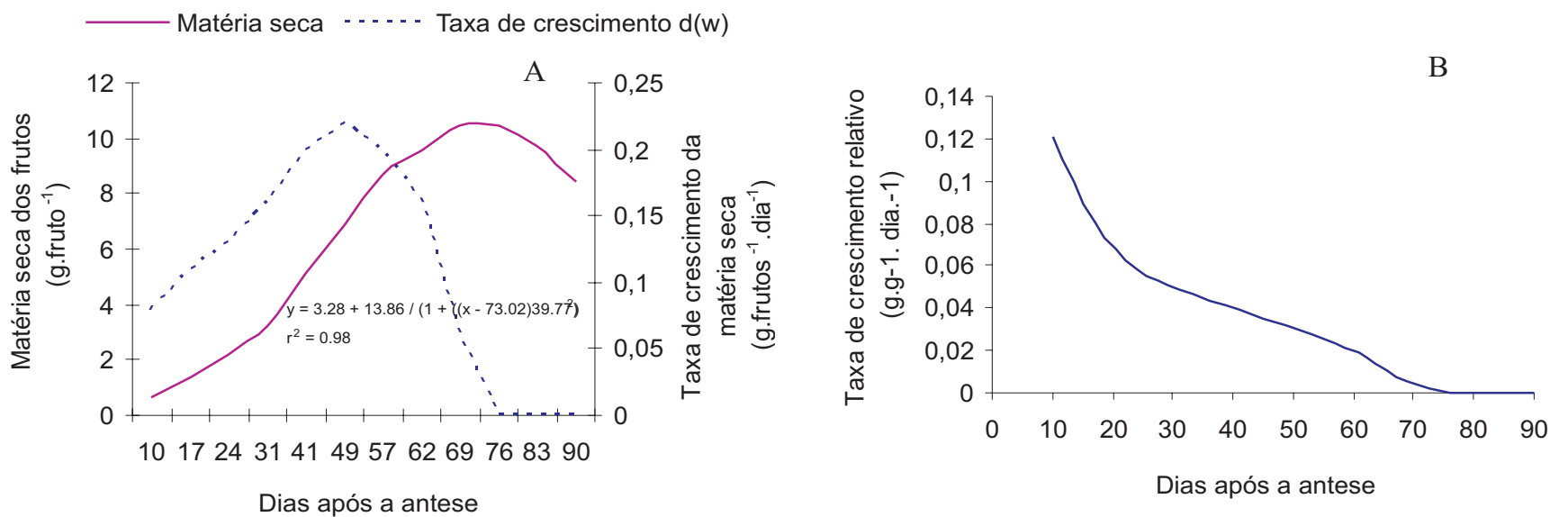

FIGURA 1. A-Matéria seca, Taxa de crescimento e B - Taxa de crescimento relativo dos frutos de urucum (Bixa orellana L.), em doze épocas de colheita após a antese, cultivado em um sistema agroflorestal. Manaus - AM. 
este período houve um declínio de matéria seca. Nesta fase os frutos começaram a secar e aos 90 DAA estavam completamente secos.

$\mathrm{Na}$ maturidade fisiológica, cessa a translocação de assimilados da planta para os frutos. Como a umidade dos frutos ainda encontrava-se relativamente alta, é normal que houvesse perda de parte da matéria seca por certo período de tempo até a umidade alcançar níveis em que o metabolismo diminua o suficiente para praticamente eliminar esta perda.

A taxa de crescimento da matéria seca dos frutos aumentou durante os primeiros dias após a antese, chegando a uma taxa máxima de $0,22 \mathrm{~g}$. fruto $^{-1} \cdot$ dia $^{-1}$, aos 49 DAA e a seguir, decrescendo rápido atingindo o valor zero a partir dos 76 DAA (Figura 1A). Quanto à tendência da taxa de crescimento relativo dos frutos, observa-se que os valores iniciais são relativamente altos até aos 31 DAA. Os valores decrescem de maneira uniforme até aos 69 DAA e após esta fase a taxa atinge valor zero. $O$ valor máximo da taxa de crescimento relativo foi de $0,12 \mathrm{~g} \cdot \mathrm{g}^{-1} \cdot \mathrm{dia}^{-1}$ aos 10 DAA (Figura 1B).

Quanto ao crescimento das sementes em relação à matéria seca, observa-se que houve um comportamento sigmoidal, com três fases distintas. O acúmulo de matéria seca no início foi lento, até os $31 \mathrm{DAA}$. Segundo Castro et al. (2004), esta fase corresponde à divisão celular e que durante essa etapa, a histodiferenciação e a morfogênese da semente acontecem à medida que o zigoto unicelular se submete a divisões extensivas e as células resultantes se diferenciam para dar forma ao embrião A segunda fase de crescimento foi acelerada, até os 69 DAA, devido à deposição de reservas nos tecidos do endosperma. Depois o crescimento foi novamente lento até aos $76 \mathrm{DAA}$, alcançando um valor máximo de matéria seca de 7,2 g. Durante esta fase, os vacúolos diminuem de tamanho à medida que os compostos de armazenamento se acumulam e o peso da matéria seca aumenta (Castro et al., 2004). Após esse período até 90 DAA houve um pequeno e lento decréscimo do acúmulo de matéria seca (Figura 2A).

O mesmo padrão de acúmulo de matéria seca que ocorreu nos frutos ocorreu nas sementes. Aos 76 DAA, a umidade das sementes ainda encontrava-se alta (62\%), (Tabela $1 \mathrm{e}$ Figura 8), portanto, seria esperado que houvesse perda de parte da matéria seca por um certo período de tempo. O conteúdo de água (relativo ao peso seco) diminui, enquanto a matéria seca substitui a água nas células (Castro et al., 2004).

A taxa de crescimento das sementes alcançou valor máximo aos 57 DAA, alcançando o valor de $0,24 \mathrm{~g} \cdot \mathrm{dia}^{-1}$ nas sementes de cinco frutos (Figura 2A).

Neste experimento observou-se que, apesar dos frutos e sementes terem atingido seus pesos de matéria seca máximos aos 76 DAA, as sementes receberem metabólitos do fruto, além dos fotoassimilados provenientes da fotossíntese. Isto pode ser confirmado porque os frutos, após terem atingido seus pesos máximos de matéria seca, por ocasião da maturação, tiveram esse valor diminuído rapidamente até a ultima colheita. Além disso, o ponto de inflexão, caracterizado pela taxa de máximo ganho de peso da matéria seca, nos frutos ocorreu aos 49 DAA, enquanto que nas sementes alcançou a taxa máxima aos 57 DAA. As sementes começaram a crescer depois dos frutos, porém após o seu surgimento passaram a ser os drenos preferenciais, o que pode ser constatado pelo fato de apresentarem maior taxa de crescimento relativo $(0,26$ para as sementes e 0,12 para os frutos).
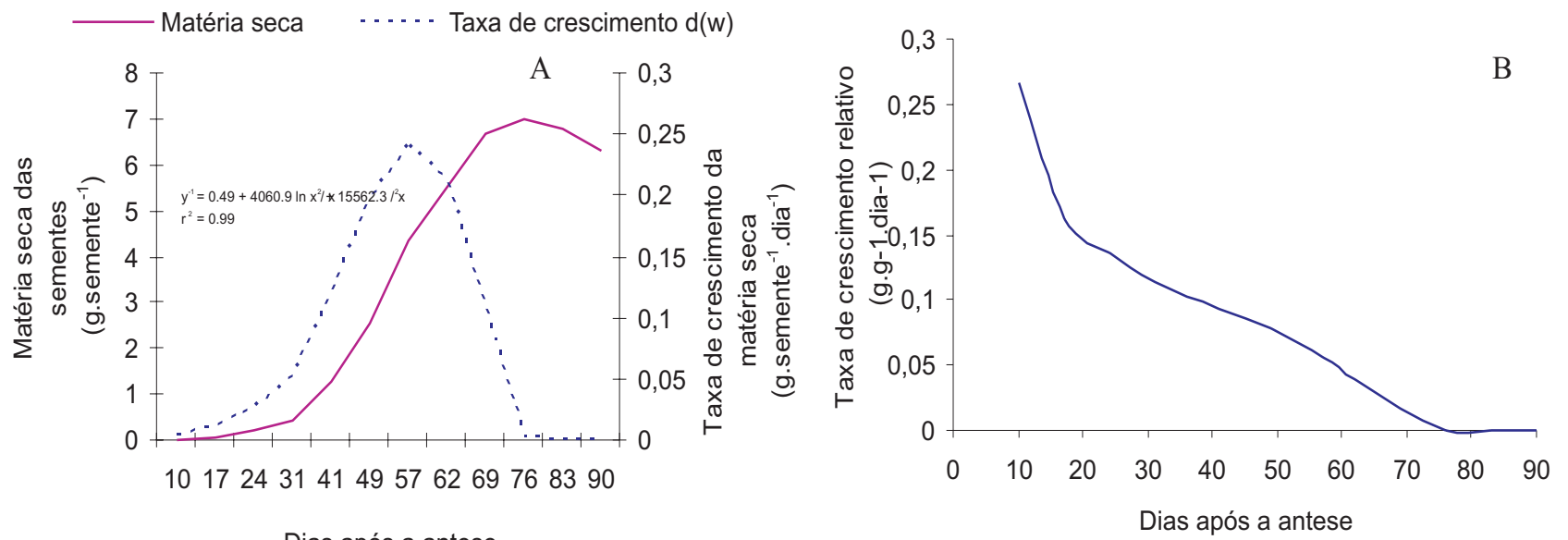

Dias após a antese

FIGURA 2. A- Matéria seca, Taxa de crescimento e B - Taxa de crescimento relativo das sementes de urucum (Bixa orellana L.), em doze épocas de colheita após a antese, cultivado em um sistema agroflorestal. Manaus - AM. 
TABELA 1. Médias de diferentes estádios de maturação das características de germinação de sementes de urucum (Bixa orellana L.), produzidas em um sistema agroflorestal. Manaus - AM.

\begin{tabular}{lcccc}
\hline $\begin{array}{l}\text { Dias após } \\
\text { a antese }\end{array}$ & $\begin{array}{c}\text { Teste de } \\
\text { germinação }(\%)\end{array}$ & $\begin{array}{c}\text { Emergência de } \\
\text { plântulas }(\%)\end{array}$ & $\begin{array}{c}\text { Índice de velocidade } \\
\text { de emergência }\end{array}$ & $\begin{array}{c}\text { Teor de água das } \\
\text { sementes }\end{array}$ \\
\hline 10 & 0,0 & 0,0 & 0,0 & 84,6 \\
17 & 0,0 & 0,0 & 0,0 & 79,6 \\
24 & 0,0 & 0,0 & 0,0 & 85,3 \\
31 & 0,0 & 0,0 & 0,0 & 84,2 \\
41 & 0,0 & 0,0 & 0,0 & 82,4 \\
49 & 0,0 & 0,0 & 0,0 & 79,2 \\
57 & 0,0 & 0,0 & 0,0 & 71,1 \\
62 & 53,0 & 59,0 & 1,47 & 68,2 \\
69 & 52,0 & 58,0 & 1,49 & 64,0 \\
76 & 78,0 & 76,0 & 1,64 & 62,3 \\
83 & 71,0 & 73,0 & 1,59 & 62,1 \\
90 & 70,0 & 61,0 & 1,58 & 59,7 \\
\hline FS** & 138,0 & 41,7 & 72,9 & 37,1 \\
DMS & 10,74 & 18,52 & 0,16 & 5,41 \\
CV $(\%)$ & 16,7 & 31,28 & 5,52 & 3,6 \\
DP & 4,35 & 7,51 & 0,06 & 2,09 \\
\hline
\end{tabular}

$\mathrm{F}^{* *}=$ significativo a $1 \%$ de probabilidade; DMS = diferença mínima significativa para épocas a $5 \%$ de probabilidade; CV $(\%)=$ coeficiente de variação; $\mathrm{DP}=$ desvio padrão da média

No início, o fruto torna-se um dreno forte, em conseqüência de altas taxas de divisão e expansão celular, com o posterior crescimento das sementes, estas passaram a ser drenos mais fortes, importando provavelmente fotoassimilados das folhas mais próximas e do próprio fruto. Apesar dos resultados mostrarem que o fruto contribuiu com assimilados para as sementes, esses não foram tão eficientes como em vagens de leguminosas (Costa et al., 1991; Figueiredo, 1996).

Observou-se que a taxa de crescimento relativo das sementes, inicialmente, foi alta até aos 17 dias após a abertura das flores, com valor máximo de $0,26 \mathrm{~g} \cdot \mathrm{g}^{-1} \cdot \mathrm{dia}^{-1}$. Os valores decrescem rapidamente, até atingir valores negativos aos 83 DAA (Figura 2 B).

$\mathrm{O}$ acúmulo máximo de matéria seca das sementes coincidiu com o máximo de matéria seca dos frutos. Apesar da variação do peso de matéria seca das sementes ser de pequena amplitude durante o processo de maturação, verificase que, à medida que se processou a maturação, o peso da matéria seca dos frutos diminuiu e o das sementes tendeu a estabilizar, ambos atingindo valores máximos por ocasião da maturação.

Neste estudo, a matéria seca das sementes de urucum foi significativa e altamente correlacionada com todas as outras características avaliadas. A porcentagem de germinação teve uma correlação significativa positiva com a matéria seca $(0,90)$, o mesmo ocorrendo para a porcentagem de emergência $(0,90)$ (Tabela 2).

Algumas pesquisas indicam que para certas espécies, o máximo vigor e germinação da semente não coincidem com o máximo peso da matéria seca da mesma. Esses estudos demonstram que diferentes características de qualidade continuam a desenvolver após as sementes terem atingido o máximo de matéria seca (Ellis e Pietra Filho, 1992; Lima Júnior, 1999). Para as sementes de urucum o máximo de matéria seca coincidiu com a máxima germinação e vigor, portanto esta característica foi bastante precisa para estimar o ponto

TABELA 2. Correlação entre as características de maturação das sementes de urucum (Bixa orellana $L$,), cultivados em um sistema agroflorestal no município de Manaus -AM,

\begin{tabular}{lc}
\hline Características & Correlação (r) \\
\hline Matéria seca $(\mathrm{g})$ X Tamanho $\left(\mathrm{mm}^{2}\right)$ & 0,933 \\
Matéria seca $(\mathrm{g})$ X Umidade $(\%)$ & $-0,974$ \\
Matéria seca $(\mathrm{g})$ X Germinação $(\%)$ & 0,905 \\
Matéria seca $(\mathrm{g})$ X Emergência $(\%)$ & 0,909 \\
Umidade (\%) X Tamanho $\left(\mathrm{mm}^{2}\right)$ & $-0,853$ \\
Umidade (\%) X Germinação $(\%)$ & $-0,920$ \\
Umidade (\%) X Emergência $(\%)$ & $-0,911$ \\
Germinação (\%) X Tamanho $\left(\mathrm{mm}^{2}\right)$ & 0,728 \\
Germinação (\%) X Emergência $(\%)$ & 0,994 \\
\hline
\end{tabular}


de maturidade fisiológica para esta espécie.

\section{Comprimento e diâmetro dos frutos}

Observou-se que o crescimento dos frutos em comprimento ocorreu em duas fases: a primeira que durou 41 DAA e a segunda até a ultima colheita com pouco ou quase nenhum crescimento. No início, o crescimento foi acelerado, depois houve um crescimento lento e aos 49 DAA alcançou o comprimento de $56,6 \mathrm{~mm}$ não diferenciando das demais colheitas, o valor máximo estimado foi de $56,1 \mathrm{~mm}$ com o qual permaneceu semelhante até a última colheita (Figura 3A).

A taxa de crescimento máximo foi alcançada aos 24 DAA com 1,41 mm. fruto ${ }^{-1}$. dia ${ }^{-1}$, depois decresceu rapidamente, porém sempre com valores positivos (Figura 3A). Inicialmente, a taxa de crescimento relativo foi alta atingindo valores máximos de $0,08 \mathrm{~mm} \cdot \mathrm{mm}^{-1} \cdot \mathrm{dia}^{-1}$ aos $10 \mathrm{DAA}$, depois decresceu rapidamente (Figura 3B). Segundo Figueiredo (1996), a preferência inicial de assimilados para a formação do fruto se dá pelo fato deste constituir estruturas que irão formar as sementes no seu interior. Na segunda etapa, já formada as estruturas do fruto, os assimilados foram translocados preferencialmente para as sementes que são as estruturas de reprodução das plantas.

O comprimento do fruto variou de $11,5 \mathrm{~mm}$ (10 DAA) a $58,5 \mathrm{~mm}$ (76 DAA). A variabilidade no comprimento do fruto de urucum foi demonstrada por Ferreira e Falesi (1989), que encontraram valores de $60 \mathrm{~mm}$ para a cultivar pastelão, $30 \mathrm{~mm}$ para verdinha, $45 \mathrm{~mm}$ (Wagner), $45 \mathrm{~mm}$ (branca) e $35 \mathrm{~mm}$ (jari). Kato et al. (1992) encontraram valores médios para comprimento de fruto de $44,2 \mathrm{~mm}$, sem mencionar a cultivar.

$\mathrm{O}$ crescimento em diâmetro dos frutos aos $62 \mathrm{DAA}$ com valores de $34,4 \mathrm{~mm}$ não diferenciou das demais colheitas, chegando ao final dos 90 DAA com $31,7 \mathrm{~mm}$ quando estavam completamente secos. A taxa de crescimento atingiu seu valor máximo aos 17 dias com $0,67 \mathrm{~mm}$. fruto ${ }^{-1} \cdot \mathrm{dia}^{-1}$, depois decresceu rapidamente chegando ao valor zero aos 83 dias (Figura 4A). A taxa de crescimento relativo inicialmente foi alta, depois decresceu rapidamente atingindo valor zero a partir dos 76 DAA (Figura 4B).

O diâmetro dos frutos variou de 7,8mm (10 DAA) a 34,6mm (69 DAA). As médias de diâmetro estudadas por Ferreira e Falesi (1989) foram de $37 \mathrm{~mm}$ (pastelão), $23 \mathrm{~mm}$ (verdinha), $42 \mathrm{~mm}$ (wagner), $30 \mathrm{~mm}$ (branca) e $20 \mathrm{~mm}$ (jari) e Kato et al. (1992), encontrou para diâmetro $28,3 \mathrm{~mm}$.

Enquanto os frutos cresceram em comprimento e esse comprimento foi mantido, o diâmetro diminuiu no final do período de crescimento. Neste período, os frutos apresentavam um achatamento nas valvas quando estavam completamente secos.

O tamanho dos frutos não foi considerado um bom índice de maturação para o urucum, visto que, a partir dos 49 DAA, não houve diferença em comprimento e diâmetro das demais coletas.

\section{Comprimento e diâmetro das sementes}

O crescimento em comprimento das sementes foi semelhante ao dos frutos. Inicialmente o crescimento foi até $31 \mathrm{DAA}$, o maior aumento do comprimento ocorreu aos 62 DAA com máximo de $5,7 \mathrm{~mm}$, não havendo diferença nas demais colheitas.

A taxa máxima de crescimento foi alcançada aos 17 DAA com $0,08 \mathrm{~mm} \cdot$ semente $^{-1} \cdot \mathrm{dia}^{-1}$, depois decresceu atingindo valor zero a partir dos 76 DAA (Figura 5A). Inicialmente a taxa de crescimento relativo foi alta, atingindo valor máximo de $0,031 \mathrm{~mm} \cdot \mathrm{mm}^{-1} \cdot \mathrm{dia}^{-1}$ aos 10 dias, depois decresceu rápida $\mathrm{e}$ linearmente, atingindo valores negativos a partir dos 76 DAA

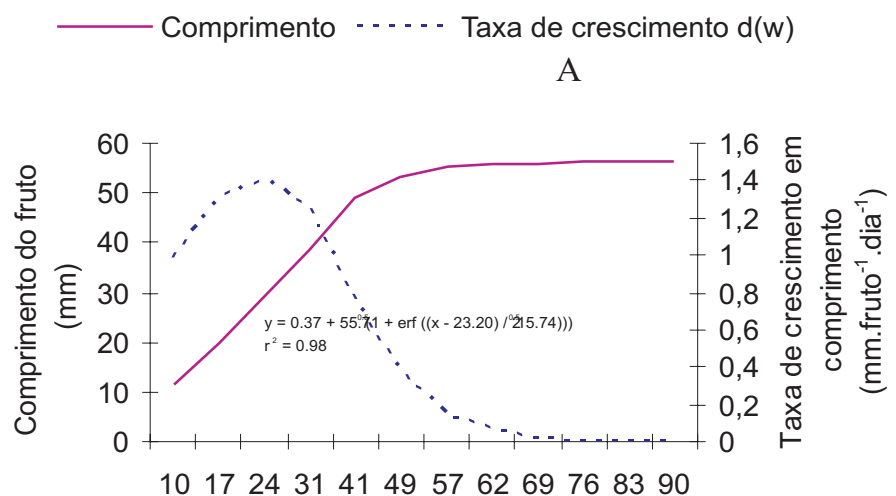

Dias após a antese

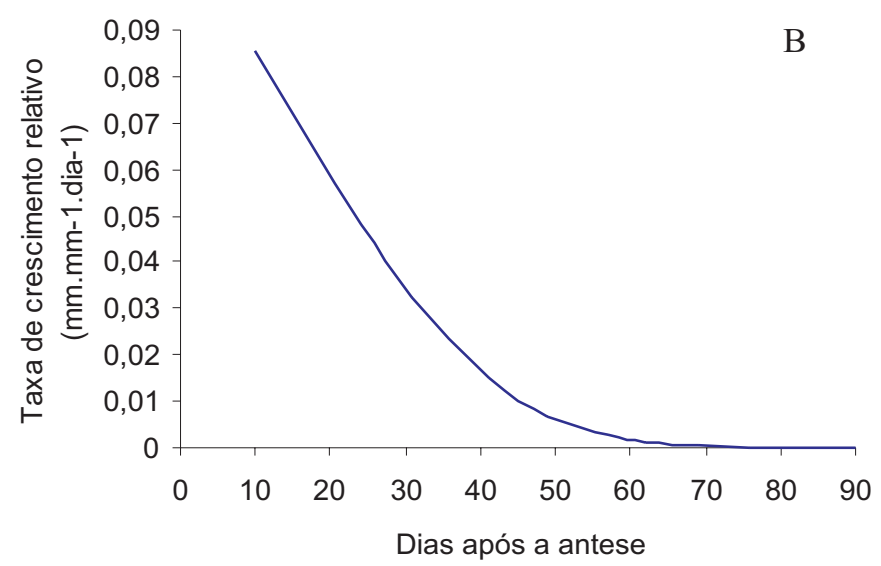

FIGURA 3. A-Comprimento, Taxa de crescimento e B - Taxa de crescimento relativo dos frutos de urucum (Bixa orellana L.), em doze épocas de colheita após a antese, cultivado em um sistema agroflorestal. Manaus - AM. 
(Figura 5B).

O crescimento em diâmetro aos 57 DAA com valores de $4,4 \mathrm{~mm}$, não diferenciou das demais colheitas posteriores. A taxa de crescimento atingiu seu valor máximo aos 10 DAA dias com 0,09mm.semente ${ }^{-1} \cdot$ dia $^{-1}$, a partir de 17 DAA decresce chegando a valores negativos aos 76 DAA (Figura 6A). A taxa de crescimento relativo em diâmetro inicialmente foi alta, depois decresceu de maneira uniforme atingindo valores negativos a partir dos 76 DAA (Figura 6B).

As sementes alcançaram tamanho e forma máximos aos 69 DAA. A partir dessa época, tanto o comprimento quanto o diâmetro estabilizaram-se até a completa maturação aos 76 DAA. Depois desse estádio, as sementes não perderam a forma, porém houve decréscimo no tamanho tanto em diâmetro quanto em comprimento. Esse comportamento é explicado pela perda de água, decorrente do processo natural de secagem após a maturação fisiológica da semente.

A taxa de crescimento relativo em diâmetro foi maior do que o comprimento, isto ocorreu porque no início de crescimento as sementes são alongadas, com seu desenvolvimento ocorreu o enchimento da semente, modificando mais o diâmetro que o comprimento. Além disso, conforme a maturação, houve também o espessamento do tegumento externo.

O número médio de sementes por fruto bicarpelar da variedade estudada foi de 51, o mesmo número médio encontrado por Kato et al. (1992). Para Falesi (1987) o número médio de sementes por fruto de urucum é de 45 sementes, podendo variar de 6 a 98, conforme o número de carpelos. Segundo Carvalho Neto (1989), o número de sementes por fruto é determinado pela característica da variedade. As variedades estudadas por Ferreira e Falesi (1989),

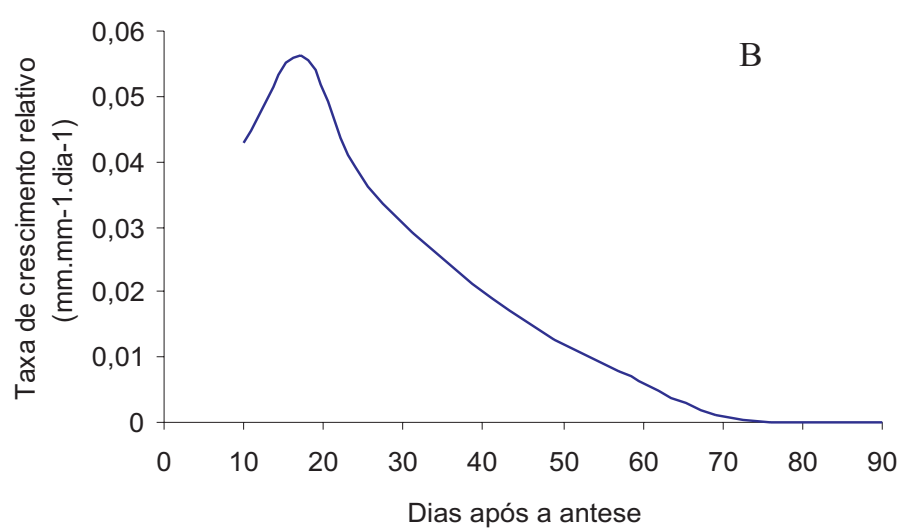

FIGURA 4. A- Diâmetro, Taxa de crescimento e B - Taxa de crescimento relativo dos frutos de urucum (Bixa orellana L.), em doze épocas de colheita após a antese, cultivado em um sistema agroflorestal. Manaus - AM.
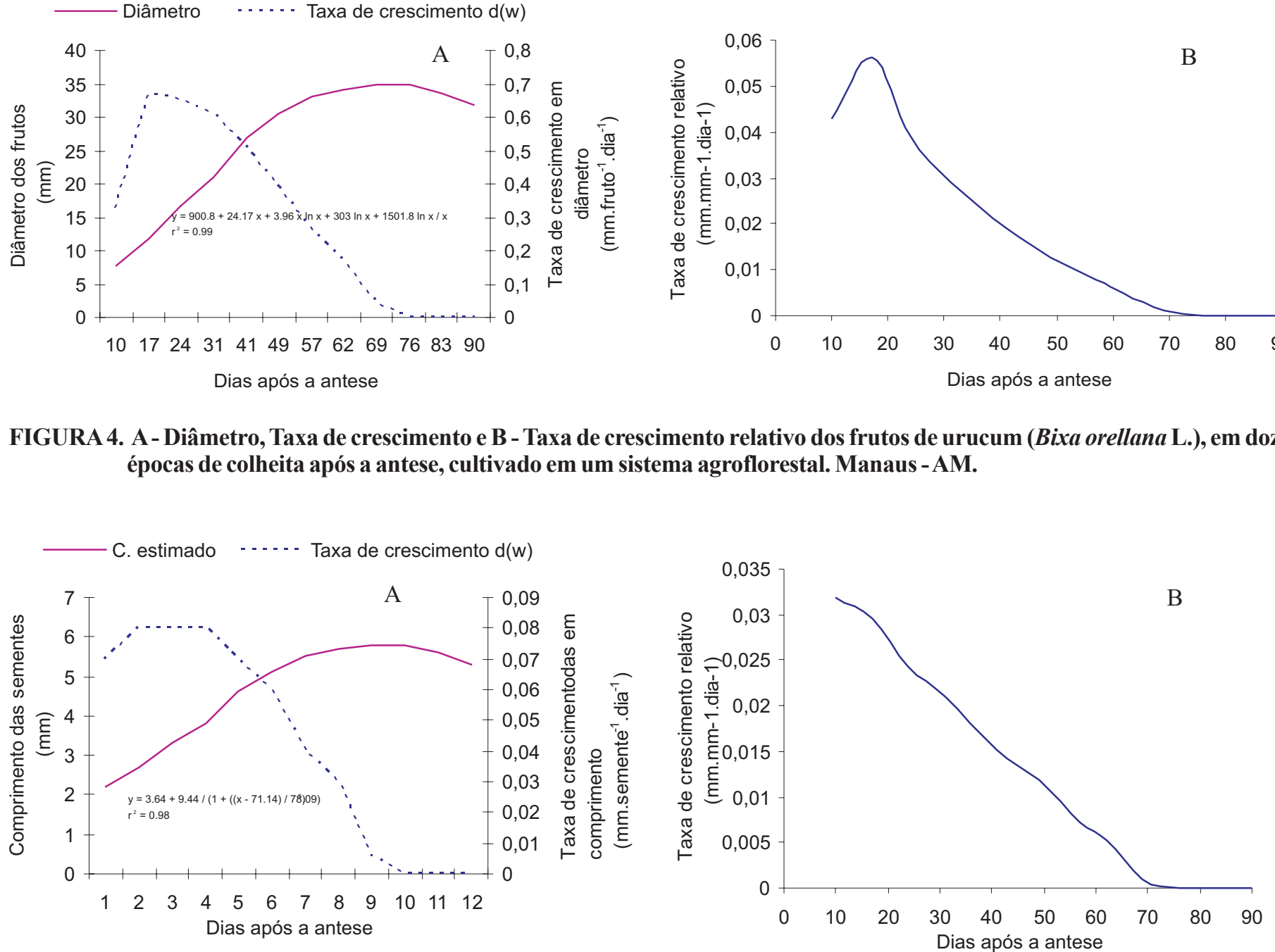

FIGURA 5. A-Comprimento, Taxa de crescimento e B - Taxa de crescimento relativo das sementes de urucum (Bixa orellana L.), em doze épocas de colheita após a antese, cultivado em um sistema agroflorestal. Manaus - AM. 

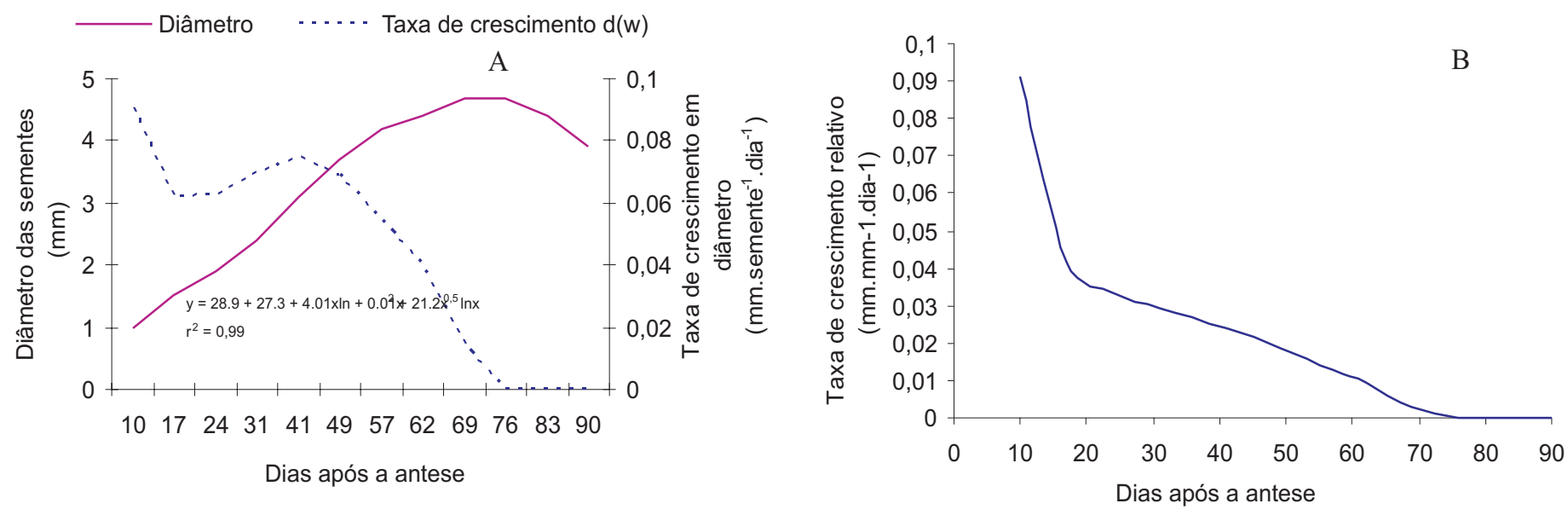

FIGURA 6. A-Diâmetro, Taxa de crescimento e B - Taxa de crescimento relativo das sementes de urucum (Bixa orellana L.), em doze épocas de colheita após a antese, cultivado em um sistema agroflorestal. Manaus - AM.

apresentaram número médio de sementes de 54 (pastelão), 45 a 65 se bi ou tricarpelares (verdinha), 45 a 80 (wagner), 51 (branca) e 48 (jari).

\section{Teor de água das sementes}

Observa-se que o teor de água das sementes na sua fase inicial de desenvolvimento é alto (Figura 7), as sementes eram constituídas quase na totalidade de água, e pouco variou com a evolução da maturação, sendo $84 \%$ aos 10 DAA e $62 \%$ aos 76 DAA.

$\mathrm{O}$ alto teor de água presente nas sementes de urucum por ocasião da sua maturação fisiológica é característico da própria espécie e fundamental para a sua sobrevivência. Esse comportamento pode ser um mecanismo de adaptação no sentido de assegurar a perpetuação da espécie, pois suas sementes são de baixa longevidade, necessitando germinar prontamente ao se desligarem da planta.

\section{Germinação e vigor das sementes}

Verifica-se que nos estádios iniciais da maturação, até 57 DAA, as sementes de urucum ainda não tinham completado suas transformações morfológicas, fisiológicas e funcionais que se processam após a fecundação do óvulo e que conferem ao embrião a capacidade de reiniciar o crescimento e, sob condições ambientais favoráveis, dar origem a uma plântula normal (Popinigis, 1977). No entanto, a partir de 62 DAA, houve aumento considerável da germinação, com 53\% e o poder germinativo continuou a crescer até aos 76 DAA atingindo $78 \%$. Depois de 83 DAA, há uma tendência de diminuir o percentual de germinação (Tabela 1).

A germinação da semente foi possível somente após estas alcançarem em média 4,5 gramas (cinco sementes) de matéria seca, o que corresponde a $62,5 \%$ do peso máximo alcançado.

$\mathrm{O}$ vigor das sementes medido pela porcentagem de emergência de plântulas teve o mesmo comportamento do

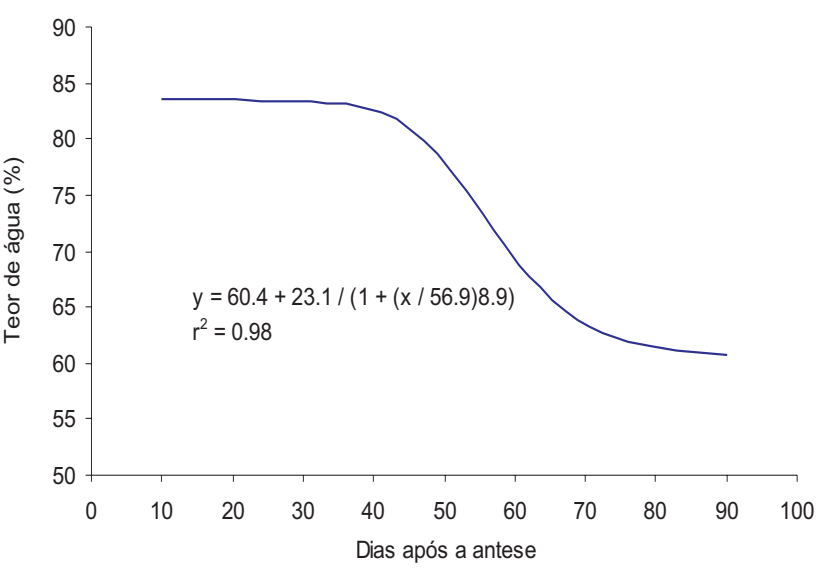

FIGURA 7. Teor de água das sementes de urucum (Bixa orellana L.), em doze épocas de colheita após a antese, cultivados em um sistema agroflorestal. Manaus AM.

teste de germinação, porém, aos 90 DAA houve uma diminuição significativa do vigor. O Índice de velocidade de emergência atingiu o máximo valor também aos 76 DAA (Tabela 1).

Possivelmente o decréscimo no poder germinativo e vigor das sementes de urucum após terem atingido a maturidade fisiológica, seja causado pela deterioração em função de condições ambientais desfavoráveis. Segundo Villela e Peres (2004) o armazenamento das sementes deve ser iniciado na maturidade fisiológica, e o maior desafio é conseguir que as sementes, após um certo período, ainda apresentem elevada qualidade fisiológica.

Kato et al. (1992), estudaram diferentes épocas de colheita de urucum em condições ecológicas de Belém-PA e encontraram tempo semelhante de maturidade fisiológica para o urucum, afirmando que este, pode estar situado entre os 
extremos de 72 e 79 dias após a abertura da primeira flor da inflorescência. Rodriguez e Enríquez (1983), trabalhando em Turrialba (Costa Rica), observaram que o tempo desde a floração até a colheita do urucum varia entre 60 a 80 dias. Porém para Lopes et al. (1992), estudando em condições ecológicas de Vitória da Conquista - BA, os melhores resultados de emergência e vigor de plântulas foram obtidos entre 130 e 140 DAA e que sementes colhidas até 120 dias DAA apresentaram baixo percentual de emergência.

\section{CONCLUSÕES}

Os frutos de urucum alcançam o peso máximo de matéria seca aos 76 dias após a antese, quando já se apresentam firmes, com pêlos de coloração vermelha opaco e superfície externa de tons amarelados.

As sementes apresentam peso máximo de matéria seca, máxima germinação e vigor aos 76 dias após a antese. Neste estádio o tegumento externo apresenta coloração vermelha escuro opaco, espesso, com a área da calaza circundada por um anel de coloração lilás e o funículo marrom claro.

$\mathrm{O}$ início da germinação das sementes ocorre aos 62 dias após a antese, quando estas alcançam em média 0,9 gramas de matéria seca, o que correspondeu a $62,5 \%$ do peso máximo alcançado.

\section{REFERÊNCIAS}

ALVAREZ, R.C.F. Comparação de duas cultivares de amendoim (Arachis hypogea L.) através do método de análise de crescimento. In: CONGRESSO BRASILEIRO DE FISIOLOGIA VEGETAL, 7., 1999, Brasília. Resumos... Brasília: EMBRAPA, 1999. v.11, p.18.Suplemento.

BENINCASA, M.M.P. Análise de crescimento de plantas (noções básicas). Jaboticabal: UNESP, 1988. 41p.

BRASIL. Ministério da Agricultura e Reforma Agraria. Regras para análise de sementes. Brasília: SNDA/DNDV/CLAV, 1992. 365 p.

CARVAlHO NETO, E.T. Cultura do urucu. 1989. 16 p. (Mimeografado).

CASTRO, R.D.; BRADFORD, K.J.; HILHORST, H.W.M. Desenvolvimento de sementes e conteúdo de água. In: FERREIRA, A.G.; BORGHETTI, F. (Ed.) Germinação: do básico ao aplicado. Porto Alegre: ARTMED, 2004. p.51-67.

COSTA R.C.L.; LOPES, N.; OLIVA, M.A. Crescimento, morfologia, partição de assimilados e produção de matéria seca em Phaseolos vulgaris L., submetido a três níveis de nitrogênio e dois regimes hídricos. Pesquisa Agropecuária Brasileira, Brasília, v.26, n.9, p.1453-1465, 1991.

ELLIS, R.H.; PIETRA FILHO, C. The development of seed quality in spring and winter cultivars of barley and wheat. Seed Science Research, Wallingford, n.2, p.9-15, 1992.

FALESI, I.C. Urucuzeiro: recomendações básicas para o seu cultivo. Belém: EMBRAPA/UEPAE, 1987.27 p.

FERREIRA, P.V. Estatística experimental aplicada à agronomia. Maceió, 1991. 437p.

FERREIRA, W.A.; FALESI, I.C. Características nutricionais do fruto e teor de bixina em urucu (Bixa orellana L.). In: BOLETIM DE PESQUISA 97. Belém: EMBRAPA/CPATU, 1989. 31p.

FIGUEIREDO, A.F. Maturação fisiológica e análise de crescimento das sementes de caupi (Vigna unguiculata (L.) Walp.) em Manaus - Amazonas. 1996. 36f. Tese (Doutorado em Ciências Agrárias) - Universidade Federal do Amazonas, Manaus, 1996.

KATO, O.R.; FIGUEIREDO, F.J.C.; BELFORT, A.J.L.; NOGUEIRA, O.L.; BARBOSA, W.C. Época de colheita de sementes de urucu: emergência e teor de corantes. Pesquisa Agropecuária Brasileira, Brasília, v.27, n.9, p.1291-1302, 1992

LIMA JUNIOR, M.J.V. Desiccation tolerance, development, maturation and storage of seeds of several tropical tree species. 1999. 155f. Tese (Doutorado) - The University of Reading, Englad, 1999.

LOPES, P.M.F.; SOUZA, I.V.B.; CAFÉ JÚNIOR, M.; SÃO JOSÉ, A.R. Emergência e vigor de plântulas de urucueiros (Bixa orellana L.) em função do período de maturação das sementes. Revista Brasileira de Corantes Naturais, v1, n.1, p.11-14, 1992.

MENDONÇA, M.S.; BARBOSA, T.C.T.S.; ARAÚJO, M.G.P.; VIEIRA, M.G. Morfologia floral de algumas frutíferas ocorrentes em Manaus. Manaus: EDUA, 2001. 56p.

MUNSEL. Soil Color Charts. Macbeth Divison of Kollmorger Corporation. 1975.

NACIF, S.R. Ontogenia e crescimento do fruto de maracujá amarelo (Passiflora edulis var. flavicarpa). 1991. 60f. Dissertação (Mestrado em Ciência Florestal) - Universidade Federal de Viçosa, Viçosa, 1991.

PEREIRA, T.S. Caracterização de plântulas de Bixa orellana L. Urucu (Bixaceae). Revista brasileira de Sementes, Brasília, v.17, n. 2, p. 243-248.

PIMENTEL, A.A.M.P. Olericultura no trópico úmido: hortaliças na Amazônia. São Paulo: Agronômica Ceres, 1985. 322 p.

POPINIGIS, F. Fisiologia das sementes. Brasília: AGIPLAN, 1977. 289p.

RODRIGUEZ, R.G.; ENRÍQUEZ, G.A. Estudo preliminar del desarrolo de ramas y biologia floral em Bixa orellana L. In: Aspectos sobre el achiote y perspectiva para Costa Rica. Costa Rica: CATIE, 1983. p.58-78.

VILLELA, F.A.; PERES, W.B. Coleta, beneficiamento e armazenamento. In: FERREIRA, A.G.; BORGHETTI, F. (Ed.) Germinação: do básico ao aplicado. Porto Alegre: ARTMED, 2004. p. $265-281$.

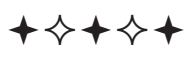

